\title{
WOMEN'S EXPERIMENTAL THEATRE E MONSTROUS REGIMENT: DUAS REPRESENTAÇÕES DE TEATROS FEMINISTAS DA DÉCADA DE 1970 ${ }^{1}$
}

\author{
Profa. Dra. Brígida de Miranda (orientadora) ${ }^{2}$ \\ Luana Tavano Garcia ${ }^{3}$
}

RESUMO: As correntes feministas norte-americanas e inglesas da década de 1960 e 1970 contribuíram para a formação de grupos de teatro compostos somente por mulheres. Este artigo faz um apanhado geral sobre estas correntes e se detém a reunir dados sobre dois grupos de teatro feministas do período, o Women's Experimental Theatre e Monstrous Regiment.

PALAVRAS-CHAVE: Feminismo, Teatro feminista, Representação de mulheres

No decorrer de meu ano como bolsista do projeto de pesquisa Poéticas do feminino e masculino: a prática teatral na perspectiva das teorias de gênero, apresentei a vontade de compreender a relação entre as mulheres e o teatro a partir de uma visão histórica dos movimentos de mulheres e feministas, iniciados nos Estados Unidos e na Inglaterra. Percebi a carência de material escrito em português sobre o assunto e, devido a esta ausência, realizei a tradução de dois textos que foram disponibilizados para o grupo de estudos sobre Teatro e Gênero: o artigo The Women's Experimental Theatre: Transforming Family Stories into Feminist Questions, escrito por Julie Malnig e Judy C. Rosenthal; e o capítulo The Discourse of Feminisms: The Spectator and Representation, do livro The feminist spectator as critic, de Jill Dolan.

Apresento neste trabalho um apanhado histórico geral sobre os feminismos ${ }^{4}$ norte-americanos e ingleses das décadas de 1960 e 1970 e como as práticas teatrais destes movimentos ocorriam, através de duas companhias de mulheres que procuraram, pela linguagem teatral, diversos modos de expressar determinadas linhas de pensamento

\footnotetext{
1 Artigo elaborado para o projeto de pesquisa Poéticas do Feminino e Masculino: A Prática Teatral na Perspectiva das Teorias de Gênero coordenado pela Dra. Brígida de Miranda

2 Professora Doutora do Departamento de Artes Cênicas do Centro de Artes (CEART) da Universidade do Estado de Santa Catarina (UDESC).

$3 \quad$ Bolsista de iniciação cientifica (PROBIC)

4 Devido ao pluralismo de categorias existentes dentro do movimento feminista, o "feminismo tem dado caminho a 'feminismos', cada um implicando distintas interpretações ideológicas e estratégias políticas” (DOLAN, 1991:3).
} 
feminista: o Women's Experimental Theatre (W.E.T), nos Estados Unidos e a

Monstrous Regiment, na Inglaterra. De acordo com Lizbeth Goodman,

Cada forma de feminismo e de teatro pode ser estudada em relação à idéia que 'teatro feminista' é um modo de representação cultural influenciada por mudanças dentro das geografias do feminismo, do estudo de mulheres, da economia, da política e dos estudos culturais (1993:3).

A década de 1960 foi um período em que questionamentos relacionados às relações sociais e políticas incitavam em muitos homens e mulheres o desejo e a luta por mudanças. A segunda onda do feminismo dos Estados Unidos floresceu a partir deste contexto. Na Inglaterra, muitas mulheres se uniram com o propósito de modificar socialmente a estrutura em que estavam inseridas, agrupando-se em movimentos que também possuíam características feministas.

Em ambos os países, no início da década de 1960,

\begin{abstract}
As mulheres que atuavam na contracultura com novos esquerdistas masculinos, começaram a questionar seus próprios papéis subordinados dentro daquele, suposto, mundo igualitário. Após as tentativas sem sucesso de mudar atitudes sexistas, várias mulheres decidiram abandonar as casas de teatro sob dominação masculina, ao mesmo tempo. Elas estavam, claro, sendo apoiadas por um nascente movimento feminista, que expunha desejos e necessidades, anteriormente não expressos. Nas artes, assim como no teatro, houve um renascimento da atividade criativa, na medida em que as mulheres descobriam talento latente como artistas, escritoras e produtoras $^{5}$ (MALNIG, ROSENTHAL apud HART, 1996:202).
\end{abstract}

As primeiras manifestações do feminismo surgiram no final do século XIX e início do XX em países como a França, Inglaterra e Estados Unidos. O movimento se revelou a partir da luta social de grupos de mulheres da classe média, para obterem o direito ao voto e melhor educação. Esta movimentação foi chamada, posteriormente, de "primeira onda" do feminismo. O "nascente" movimento feminista que Malnig e Rosenthal apontam refere à segunda onda do feminismo, que ocorreu nas décadas de 1960 e 1970.

De acordo com Brígida Miranda,

a necessidade de criar outros modelos de representação da mulher na arte, especificamente no teatro, foi uma das principais motivações para que nesses 'espaços de mulheres' e/ou 'espaços feministas' houvesse uma grande produção de textos teatrais $(2008: 286)$.

Todas as traduções foram feitas pela autora. 
Dolan relaciona as correntes da segunda onda do feminismo norte-americano com as tendências teatrais que as mulheres adotavam para transmitir suas ideologias e integrarem este meio artístico que ainda apresenta supremacia masculina na elaboração da sua prática e teoria. Dolan separa estes feminismos em três grandes correntes: o feminismo liberal, o feminismo cultural ou radical e o feminismo materialista.

O feminismo liberal pretendia equivaler em direitos a mulher e o homem, incorporando as características femininas dentro do universal masculino. As dramaturgas que faziam parte desta corrente "aceitam a noção que o teatro se comunica universalmente e preferem não serem particularizadas como mulheres" (DOLAN, 1991: 4). As peças que representavam esta corrente encaixavam-se no chamado "circuito comercial”, como a Broadway, por exemplo. Mas, de acordo com Dolan, apesar de os esforços do feminismo liberal terem sido responsáveis por uma maior visibilidade de escritoras, diretoras e produtoras teatrais, para a crítica feminista este pensamento acarretava a neutralização de uma política feminista, já que estas mulheres apresentavam o desejo de "se tornarem parte do sistema que historicamente as excluíram" (Idem:5).

O feminismo Cultural, também chamado de radical, propunha "uma mudança fundamental na natureza da universalidade, sugerindo que os valores do gênero feminino tomem o lugar do genérico masculino" (DOLAN, 1991:6). A relação hierárquica de poder se mantinha nesta visão, porém invertida, e as especificidades femininas eram consideradas mais valorosas do que as masculinas.

O grupo Women's Experimental Theatre foi fundado por Clare Coss, Sondra Segal, e Roberta Sklar no início da década de 1970 na cidade de Nova York. Em dez anos, produziu diversas peças e performances e representava o pensamento e as práticas relacionadas ao feminismo cultural. Roberta Sklar participava como co-diretora do Open Theatre, juntamente com Joseph Chaikin, mas deixou o grupo ao perceber sua impossibilidade de se desenvolver completamente como artista e feminista. A fundadora do W.E.T faz referência à falta de espaço que a prática do grupo tinha em relação às feministas liberais:

A tentação de fazer parte da tradição masculina é ainda maior do que costumava ser, pois mais mulheres foram permitidas adentrá-la. Mas os temas e as formas a serem exploradas por mulheres, através de uma perspectiva de identificação-feminina, raramente foram incluídas (SKLAR apud HERBERT, 2006:2). 
Para Dolan "o relacionamento de mãe/filha se torna paradigmática do conteúdo do teatro feminista cultural" (1991: 9). Esta relação pode ser observada no primeiro e mais conhecido trabalho do W.E.T: a trilogia The Daughters Cycle (1977-81). A trilogia foi uma

\begin{abstract}
incisiva e, muitas vezes, profundamente perturbadora exploração teatral sobre mulheres dentro da família patriarcal do Ocidente. Cada uma das três peças, Daughters, Sister/Sister, e Electra Speaks, reflete uma contínua jornada das mulheres protagonistas, enquanto elas perpassam a infância, adolescência e fase adulta, até que Electra finalmente encontra sua voz e deixa o confinamento da casa (MALNIG, ROSENTHAL apud HART, PHELAN, 1996:201).
\end{abstract}

Já a segunda trilogia do grupo, Women-s body and Other Natural Resources (1980-85), integrava performances que expunham o relacionamento das mulheres com seus corpos e com a comida. O W.E.T empregava uma técnica de atuação chamada Fast talk, em que as atrizes "vomitavam” palavras e expressões faciais diante do público. A técnica refletia o que o grupo considerava a obsessão natural da experiência interior das mulheres e permitia às atrizes articularem sentimentos e desejos anteriormente não expressos e silenciados. O direcionamento direto à platéia também era um recurso utilizado pelo grupo.

O teatro radical feminista se apropriou da corrente experimentação de teatro performático para uma estética especificamente feminina: grupos como o Women's Experimental Theatre [....] fizeram suas peças de forma não lineares, resistiram a autoridade do fechamento narrativo, usaram estilo de documentário e direcionamento direto ao publico. A prevalecência destas técnicas, assim como a importância da conscientização indicam um esforço para subverter os dualismos entre a arte e a vida, entre atores e a platéia (WALSH, 1993).

A tendência essencialista era representada no palco através de uma textualidade corporal feminina, invertendo a autoridade do texto para o privilégio do corpo e do gesto como essência primordial. Andrea Nye cita a dramaturga Hèléne Cixous, que também integrava na sua escrita o pensamento feminista cultural:

Na escrita da mulher será ouvido o ritmo da expressão sentida e o ímpeto do fôlego que fará o texto 'ofegar', sacudido de gritos. Será ouvida a voz que exclama os sofrimentos e gozos do corpo, uma espécie de carne cantante que existia antes da lei patriarcal, antes que o 'fôlego fosse sufocado pelo simbólico.' (CIXOUS apud NYE, 1995:238) 
A crítica teatral feminista a esta corrente, no entanto, defende que "unir a sexualidade da mulher à sua textualidade oferece uma posição de sujeito cravada em universalismos transcendentes" (DOLAN, 1991:8). As diferenças de etnia, classe social e opção sexual entre as mulheres não eram consideradas, já que "enquanto suas diferenças sexuais dos homens são reforçadas, suas diferenças de outras mulheres são ignoradas [...] todas as diferenças são molduradas em termos de igualdade definida pela separação da mulher do homem" (Idem: 9). Estes fatores acarretaram a projeção de uma espectadora feminista ideal e transcendental.

Por causa da crítica e da mudança dentro dos movimentos de mulheres, em que clarificava a luta contra questões como diferenças sexuais, de classe e de raça dentro de suas comunidades, o W.E.T percebeu que não podia mais depender dos laços que, uma década antes, existiam entre a companhia e seu público. Roberta Sklar reconhece que "algumas coisas estavam acontecendo nos movimentos feministas que não havíamos percebido" (MALNIG, ROSENTHAL, apud HART, PHELAN, 1996:212). Em 1985, Cross e

Segal param de produzir peças teatrais, mas de acordo com Malnig e Rosenthal,

O trabalho do Women's Experimental Theatre ainda é, entretanto, uma reflexão expansiva da política feminista, trazendo à tona importantes questões para os primeiros movimentos feministas (Idem:212).

Já o feminismo materialista, terceira corrente do feminismo norte-americano, enquadra o debate de gênero sob termos de neutralidade de gênero, o que as duas outras correntes não faziam. As feministas materialistas "desconstroem o sujeito mítico Mulher, para olhar para as mulheres como uma classe oprimida por condições materiais e relações sociais" (DOLAN, 1991: 10). No discurso materialista, gênero não é inato. Ele é ditado através da culturalização, uma vez que as divisões de gênero são situadas a serviço da ideologia da cultura dominante.

A escrita e a prática teatral das mulheres que representam o pensamento feminista materialista convergem no esforço de provocar uma "desnaturalização" do processo psicológico de identificação, implícito na representação teatral:

Invés de ser seduzida por uma narrativa que oferece uma posição confortável de gênero, a espectadora é convidada a prestar atenção crítica para a ideologia de gênero que o processo de representação historicamente produz e às opressivas relações sociais que ela legitimiza (DOLAN, 1991:14). 
Na Inlgaterra, durante as décadas de 1960 e 1970, os movimentos feministas ressurgem com um olhar crítico voltado para as questões socialistas dos direitos das mulheres. De acordo com Lizbeth Goodman,

Os feminismos americanos reagiram contra o 'patriarcado' em termos objetivos e simbólicos influenciados pela estrutura capitalista da economia. Um dos resultados é o prevalecimento do feminismo materialista na America em oposição ao prevalecimento do feminismo socialista na Inglaterra" (1993:.35).

Apesar do feminismo socialista prevalecer na Inglaterra, outras linhas de pensamento feministas apareceram, como o essencialismo de feministas radicais. Estas distintas visões provocaram discordância entre os grupos de mulheres na Conferência Nacional para a Libertação da Mulher (National Women's Liberation Conference), em Birmingham em 1978. De acordo com Reinelt,

feministas radicais teorizaram uma subjeção trans-histórica das mulheres aos homens no patriarcado como o problema central e fato da realidade [...] a resposta socialista foi que a real haste da opressão do capitalismo e das mulheres não deve abandonar o seu lugar histórico na luta contra isso, se engajando em um movimento burguês liberal (REINELT, 1990:51).

A companhia Monstrous Regiment foi formada em 1975, na Inglaterra, e era considerada uma companhia de teatro que apresentava preocupação em tratar de questões feministas e socialistas. A formação original do Monstrous Regiment era composta pelas atrizes Mary McCusker e Gillian Hanna, mas logo Chris Bowler começou a trabalhar com o grupo como escritora/diretora e Rose Sharp como a produtora. De acordo com Goodman, "o grupo iniciou com o comprometimento de evidenciar o trabalho e as experiências de mulheres, mas não excluía homens, a princípio. Porém, em 1980 já não havia homens trabalhando com o grupo” (1993:70).

Com o passar dos anos, muitas mulheres integraram a companhia, que por quinze anos teve o objetivo de reunir "material feminista sobre tópicos históricos, com inclinações multiculturais, desenvolvidas através da escrita de jovens escritoras" (REINELT apud HART, PHELAN, 1996:166).

Gillian Hanna, em uma entrevista a Lizbeth Goodman, revelou que,

Quando você fala do Monstrous Regiment como um grupo feminista, você precisa fazer uma distinção entra a estrutura organizacional da companhia e o trabalho que aparece no palco. O Regimento foi estabelecido nas bases dos princípios feministas... Não foi tudo reunido em um só momento [...] Nós 
éramos um grupo de pessoas diversificadas, e tivemos que estabelecer nossas regras através do processo coletivo durante o caminho (GOODMAN, 1993:16).

O grupo realizou variadas performances e encenou diversas peças, entre elas, Vinegar Tom (1978). Ecrita por Caryl Churchill, a peça apresenta a história de algumas mulheres condenadas por bruxaria em Essex, Inglaterra, no século XVII. O texto dramático contém uma estrutura brechtiana de narrativa e tem sete letras de músicas com caráter contemporâneo, inscritas para contrastar com o andamento das cenas.

Ao contextualizar os acontecimentos como fatos históricos e distanciados através das técnicas de estranhamento ${ }^{6}$, a espectadora é instigada a questionar a sua própria realidade. Para Goodman, "uma questão que a teoria feminista repetidamente chama atenção é para o fato de que o discurso tem uma maneira de construir falsos universos e de fazê-los parecerem naturais" (1993: 22). De acordo com Janelle Reinelt,

\footnotetext{
Para as feministas, técnicas brechtianas oferecem um caminho para examinar as condições materiais de comportamento de gênero (como eles são internalizados, opostos e modificados) e sua interação com fatores sóciopolíticos como a classe (1990:50).
}

Com o passar dos anos, e principalmente durante o período final da influência da primeira-ministra inglesa Margareth Thatcher, o Monstrous Regiment enfrentou problemas financeiros e seu término ocorreu quinze anos após sua fundação. Um dos motivos que contribuiu para a falta de investimentos foi o fato que,

\footnotetext{
como elas estavam comprometidas em desenvolver uma nova escrita, seus "scripts" freqüentemente atravessavam extensos workshops e estágios preparatórios, levando vários anos para progredir da primeira idéia até a produção final de seus trabalhos (REINELT apud HART, PHELAN, 1996:162).
}

Sem a verba necessária para pagar os membros da companhia, a Monstrous Regiment continha a presença de poucos personagens nas suas produções, o que resultava em experiências individuais e psicológicas invés retratar a natureza dialética da vida em sociedade de diversos grupos, como ocorreu em Vinegar Tom:

\footnotetext{
$6 \quad$ Em alemão, verfremdungseffekt. Traduzido como estranhamento para a língua portuguesa (ou distanciamento, de acordo com alguns autores), a palavra representa um conjunto de recursos literários e cênicos que visam romper com a identificação do espectador em relação à trama representada, como era comum acontecer no teatro Aristotélico, ou "dramático", na primeira metade do século XX.
} 
Enquanto trabalhos recentes como Origin of the Species (1983), parcialmente atingem esses efeitos (de historização da narrativa) sem a visão de um elenco numeroso, existe uma inquestionável relação teatral entre o tamanho do elenco e as políticas de sua representação (Idem, 1996:167).

O estudo destas correntes feministas e das tendências teatrais dos dois grupos pesquisados abre uma perspectiva histórica e permite o fornecimento de material para futuros trabalhos sobre as relações entre as mulheres e o teatro. Detive-me a estudar estes dois grupos, pois minha curiosidade em detectar como variadas linhas de pensamento relacionadas à figura feminina e ao papel performativo do gênero dentro de dois discursos feministas claros, foram representadas.

De um lado, através das performances do Women's Experimental Theatre, a defesa de um teatro essencialmente "feminino", em que o corpo da mulher representava a imagem central, como mãe, como sexo e através das relações entre homens e mulheres. Do outro, através do Monstrous Regiment, a perspectiva histórica utilizada como ferramenta para contextualizar um discurso sobre gênero como categoria socialmente e culturalmente construída e diretamente relacionada às vertentes de classe social, etnia e opção sexual. 
DOLAN, Jill. The feminist Spectator as Critic. Michigan: University of Michigan Press, 1991.

GOODMAN, Lizbeth. Contemporary Feminist Theatres: To Each Her Own. London: T.J. Press Ltd, 1993

HERBERT, Michelle. Feminism in Theatre: Mobilization of the Third Wave. 2006. Disponível em:

http://www.associatedcontent.com/article/101931/feminism_in_theatre_mobilization_of html?page $=2$

MALNIG, Julie, ROSENTHAL, Judy C. The Women's Experimental Theatre: Transforming Family Stories into Feminist Questions. In: HART, Lynda and PHELAN, Peggy. Acting out: feminist performances. USA: University of Michigan Press, 1996. (p. 201-214)

MIRANDA, Maria Brígida de. Quem tem medo do teatro feminista? A experiência de Vinegar Tom: da pesquisa à sala de aula. Blumenau: Anais da I Jornada Latinoamericana de Estudos Teatrais, 2008.

NYE, Andrea. Teoria feminista e as filosofias do homem. Trad. Nathanael C. Caixeiro. Rio de Janeiro: Rosa dos Tempos, 1995.

REINELT, Janelle. Resisting Thatcherism: The Monstrous Regiment and the School of Hard Knox. In: HART, Lynda and PHELAN, Peggy. Acting out: feminist performances. USA: University of Michigan Press, 1996. (p. 161-180)

Beyond Brecht: Britain's New Feminist Drama. In: CASE, SuaEllen (org.). Performing feminisms: feminist critical theory and theatre. Baltimore: John Hopkins Univ. Press, 1990.

WALSH, Richard. Radical Theatre in the Sixties and Seventies. British Association for American Studies. N. 24, 1993. Disponível em:

http://www.baas.ac.uk/resources/pamphlets/pamphdets.asp?id=24\#ch3 